\title{
What climate sensitivity index is most useful for projections?
}

\section{Article}

Published Version

Grose, M. R., Gregory, J., Colman, R. and Andrews, T. (2018) What climate sensitivity index is most useful for projections? Geophysical Research Letters, 45 (3). pp. 1559-1566. ISSN 0094-8276 doi: https://doi.org/10.1002/2017GL075742 Available at https://centaur.reading.ac.uk/75238/

It is advisable to refer to the publisher's version if you intend to cite from the work. See Guidance on citing.

To link to this article DOI: http://dx.doi.org/10.1002/2017GL075742

Publisher: American Geophysical Union

All outputs in CentAUR are protected by Intellectual Property Rights law, including copyright law. Copyright and IPR is retained by the creators or other copyright holders. Terms and conditions for use of this material are defined in the End User Agreement.

\section{www.reading.ac.uk/centaur}

\section{CentAUR}

Central Archive at the University of Reading

Reading's research outputs online 


\section{Geophysical Research Letters}

\section{RESEARCH LETTER}

10.1002/2017GL075742

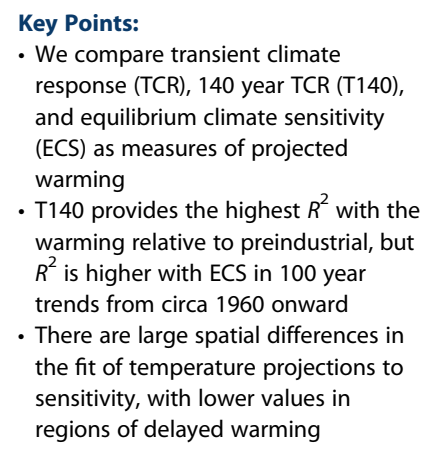

-We compare transient climate response (TCR), 140 year TCR (T140), and equilibrium climate sensitivity (ECS) as measures of projected warming

- T140 provides the highest $R^{2}$ with the warming relative to preindustrial, but $R^{2}$ is higher with ECS in 100 year trends from circa 1960 onward

- There are large spatial differences in the fit of temperature projections to sensitivity, with lower values in regions of delayed warming

Supporting Information:

- Supporting Information S1

Correspondence to:

M. R. Grose,

michael.grose@csiro.au

\section{Citation:}

Grose, M. R., Gregory, J., Colman, R., \& Andrews, T. (2018). What climate sensitivity index is most useful for projections? Geophysical Research Letters, 45, 1559-1566. https://doi.org/ 10.1002/2017GL075742

Received 22 SEP 2017 Accepted 17 JAN 2018 Accepted article online 29 JAN 2018 Published online 10 FEB 2018

\section{What Climate Sensitivity Index Is Most Useful for Projections?}

\author{
Michael R. Grose ${ }^{1}$ iD, Jonathan Gregory ${ }^{2}$ iD, Robert Colman ${ }^{3}$, and Timothy Andrews ${ }^{4}$ \\ ${ }^{1}$ CSIRO Climate Science Centre, Hobart, Tasmania, Australia, ${ }^{2}$ University of Reading, Reading, UK, ${ }^{3}$ Bureau of Meteorology, \\ Docklands, Victoria, Australia, ${ }^{4}$ Met Office, Exeter, UK
}

\begin{abstract}
Transient climate response (TCR), transient response at 140 years (T140), and equilibrium climate sensitivity (ECS) indices are intended as benchmarks for comparing the magnitude of climate response projected by climate models. It is generally assumed that TCR or T140 would explain more variability between models than ECS for temperature change over the 21 st century, since this timescale is the realm of transient climate change. Here we find that TCR explains more variability across Coupled Model Intercomparison Project phase 5 than ECS for global temperature change since preindustrial, for 50 or 100 year global trends up to the present, and for projected change under representative concentration pathways in regions of delayed warming such as the Southern Ocean. However, unexpectedly, we find that ECS correlates higher than TCR for projected change from the present in the global mean and in most regions. This higher correlation does not relate to aerosol forcing, and the physical cause requires further investigation.
\end{abstract}

\section{Introduction}

Quantifying the sensitivity of climate to the radiative forcing due to increase in atmospheric $\mathrm{CO}_{2}$ concentration is a crucial problem for making climate projections (Collins et al., 2013). An accurate estimate of sensitivity and the correct simulation of this sensitivity in climate models are essential for projecting temperature change for the globe with some accuracy (Grose et al., 2016). Also, forced change in global mean temperature is found to correlate with forced changes in regional temperature and other variables including rainfall (Mitchell, 2003; Seneviratne et al., 2016; Tebaldi \& Arblaster, 2014; Whetton et al., 2007).

Sensitivity depends on feedbacks arising from redistributions of heat within the physical earth system (atmosphere, ocean, land, and sea ice), which together strongly influence the magnitude of the climate response under a given emissions pathway. Indices of sensitivity in models are defined in terms of the magnitude of change in global mean surface air temperature (GMSAT) for a given forcing. There are two commonly used indices of sensitivity, defined for given scenarios and time frame, namely, the equilibrium climate sensitivity (ECS) and the transient climate response (TCR).

The ECS is the steady state change in GMSAT with respect to the initial state under doubled $\mathrm{CO}_{2}$. The Intergovernmental Panel on Climate Change (IPCC) Fifth Assessment Report (AR5) gave a likely range of 1.5 to $4.5^{\circ} \mathrm{C}$ (Collins et al., 2013; IPCC, 2013). For the Coupled Model Intercomparison Project phase 5 (CMIP5) global climate models (Taylor et al., 2012), ECS is not calculated from models actually run to equilibrium under doubled $\mathrm{CO}_{2}$, as this would take thousands of model years. Instead, ECS is generally estimated by extrapolation to equilibrium under constant $\mathrm{CO}_{2}$-in $\mathrm{CMIP5}$ - using "abrupt4x $\mathrm{CO}_{2}$ " experiments 150 years long, in which $\mathrm{CO}_{2}$ is instantaneously quadrupled at the start (Andrews et al., 2012; Gregory et al., 2004). The range in CMIP5 models is 2.1 to $4.6^{\circ} \mathrm{C}$ (Table S1 in the supporting information). An estimate of ECS made in this way from a nonequilibrium experiment is sometimes called "effective climate sensitivity" (Murphy, 1995), but we will refer to it as ECS for convenience. ECS depends on feedbacks in the atmosphere (water vapor, cloud, lapse rate, and albedo) and surface (sea ice, snow cover, and vegetation cover), patterns of change in sea surface temperature (SST), and ocean heat storage.

The TCR is the change in GMSAT with respect to the initial state at the time $\mathrm{CO}_{2}$ reaches double its initial concentration in the " $1 \mathrm{pctCO}_{2}$ " scenario (increase at $1 \%$ per year). Specifically, TCR is calculated as the difference in GMSAT from the start of the simulation and a 20 year period centered on the time of doubling (70 years), and the point of quadrupling (140 years) for T140. For the AR5, TCR was estimated from various lines of evidence to be in the likely range of 1.0 to $2.5^{\circ} \mathrm{C}$. The range in CMIP5 models assessed is 1.1 
to $2.5^{\circ} \mathrm{C}$ (Table S1). TCR is smaller than ECS because ocean heat uptake delays surface warming (Gregory \& Forster, 2008), and the importance of this effect is model and time dependent (Gregory et al., 2015; Kuhlbrodt \& Gregory, 2012). As the climate evolves, there is a balance between the ocean heat uptake and climate feedbacks in determining the overall surface temperature response. In all CMIP5 models, T140 is more than double TCR (Gregory et al., 2015).

The abrupt $4 \mathrm{xCO}_{2}$ and $1 \mathrm{pctCO}_{2}$ simulations used to diagnose these indices feature only changes in greenhouse gases, with no volcanic eruptions, change in anthropogenic aerosol emissions, land use change, solar output, or ozone depletion. This is different from the Representative Concentration Pathways (RCPs) of van Vuuren et al. (2011), used in AR5 for 21st century projections, which feature time-varying trajectories of each climate forcing agent. Given the influence of other forcings, the correlation between each index and projected temperature change under the RCPs is expected to be less than one. However, the correlation across models of the values of a sensitivity index with the RCP temperature projections is an indication of the usefulness of that index as an indicator of the magnitude of projected climate change to be expected. A high goodness of fit means that we can expect a model with a high value of the index to make a projection of large change under the RCP, while a model with a low value will give a small change. This helps in understanding the spread in RCP projections, and offers the potential to set constraints on future global or regional projections, by making an independent estimate of the relevant index from observational or paleoclimate records (Masson-Delmotte et al., 2013, and references therein).

Here we assess the relationship of ECS, TCR, and T140 to GMSAT and regional temperature change projected during this century by CMIP5 models at different time frames. We assess how "useful" each sensitivity index is by its ability to explain the distribution of model projections (in terms of the correlation, not the magnitude of the warming). Section 2 outlines the methods and the CMIP5 models/experiments used, section 3 presents the results for both global and regional temperature change. Discussion and conclusions are given in section 4.

\section{Models and Methods}

Model output was taken from a subset of up to 24 CMIP5 models (Table S1). TCR and ECS were taken from Flato et al. (2013), and values of T140 were taken from Gregory et al. (2015), or else calculated from model output. GMSAT was calculated from the Run1 of the historical simulations linked to three RCPs: RCP8.5, RCP4.5, and RCP2.6, for the period 1861-2100 (data were unavailable for some simulations in 1850-1860). Data were available from 20 of the 24 models for RCP2.6, and ECS values were available for 21 of the 24 models, with 18 models having both ECS values and RCP2.6 simulations available (Table S1). Here we used sensitivity measures and temperature change calculated from surface air temperature only (not blended surface air temperature-SST) and use the global mean without any mask, so the results are not directly comparable to those calculated from observed data sets (Cowtan \& Way, 2014; Richardson et al., 2016). Also, CMIP5 models are not independent, and the model set includes models with similar genealogy such as ACCESS and Hadley Centre models (Knutti et al., 2013).

We examined the time series of GMSAT from each simulation and calculated the simulated temperature change between the start of the simulation (taken as preindustrial, PI) and each subsequent year. To minimize the effect of unforced interannual variability on the estimate of forced temperature change, we considered periods of 20 years to represent individual years: values for the first (last) 9 years of each simulation are represented by the values calculated from 20 year fitted linear trends starting (ending) on those years. Values for all other years are represented by the mean of the 20 years centered on those years. A linear model is fitted to this simulated temperature change in each model and each of the three sensitivity indices (simple linear regression with slope and constant), and the coefficient of determination $\left(R^{2}\right)$ was calculated. Thus, we obtain an $R^{2}$ between temperature change and sensitivity across the range of 18 to 24 models (see Figure 1a) for temperature change in each year. $R^{2}$ is the square of the correlation coefficient, and related to the variance in GMSAT change between models explained by each index. We also test fitting a linear model with the intercept specified as zero (simple linear regression with no constant), which assumes the warming is proportional to the magnitude of the index, and calculating the coefficient of determination of this simpler model $\left(R_{0}^{2}\right)$ (Figure $\mathrm{S} 1$ ). 

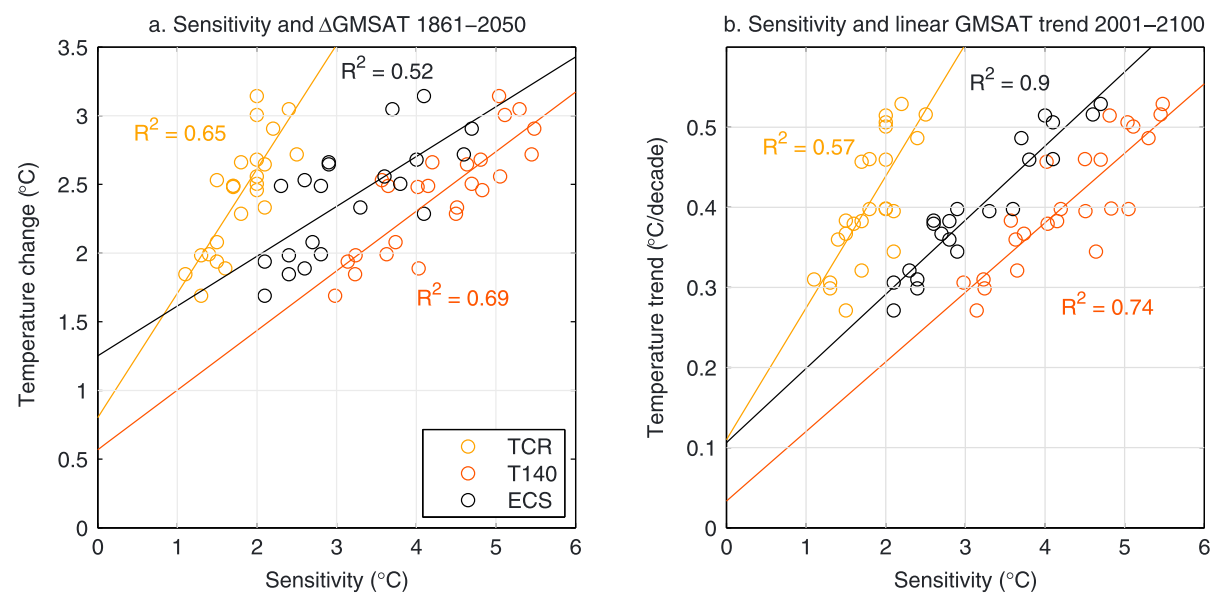

Figure 1. Scatterplot of sensitivity estimates (transient climate response (TCR), T140, and equilibrium climate sensitivity (ECS)) and temperature change under RCP8.5; (a) change in global mean surface air temperature (GMSAT) between 1861 and 2050; (b) temperature trend in 2001-2100. Linear fits are shown and extrapolated back to the intercept and the coefficient of determination $\left(R^{2}\right)$ is noted.

The use of GMSAT since the PI era is relevant to policy targets for warming; however, studies looking at changes and trends over time frames for societal planning and adaptation may be more interested in shorter term trends, and in trends starting later than PI. Therefore, we also look at the linear trend in GMSAT within a 100 year moving window (commensurate with climate projections for the 21st century, see an example in Figure $1 \mathrm{~b}$ ), and a 50 year moving window (commensurate with climate projections time frames such as 2000-2050). The $R^{2}$ of the intermodel spread in GMSAT change and each sensitivity index is also examined in simulations from the $1 \% \mathrm{CO}_{2}$ and abrupt $4 \times \mathrm{CO}_{2}$ experiments.

The spatial distribution of the correlation between climate sensitivity and temperature projections of the $21 \mathrm{st}$ century is shown by the $R^{2}$ between each global index and the change in SAT in each model cell under RCP8.5 between 1986-2005 and 2080-2099 (a commonly reported period in climate projections, global values of this projection given in Table S1). Model outputs were first regridded to a common $1.5^{\circ} \times 1.5^{\circ}$ latitude/longitude grid.

\section{Results}

Before examining the RCPs, it is instructive to consider the fit of temperature change and climate sensitivity with simplified forcing experiments (Figure S2). The intermodel spread in the relatively steady increase in GMSAT in the $1 \% \mathrm{CO}_{2}$ simulations has a high $R^{2}$ with TCR at $\sim 70$ years and with $\mathrm{T} 140$ at $\sim 140$ years, as expected. TCR has higher $R^{2}$ with temperature change than ECS does throughout the period. Under the strong "impulse" forcing of the abrupt $4 \mathrm{XCO}_{2}$ simulations, there is a rapid increase then plateau of GMSAT. In these simulations, the $R^{2}$ of the intermodel spread of temperature change with ECS is high and increasing in the last 50 years of the simulations as expected when the warming is well advanced, and also a high $R^{2}$ with T140 throughout. The uncertainty in $R^{2}$ is estimated by using a 1,000-member bootstrap of random sampling with replacement from the empirical distribution, and the \pm 1 standard deviation is plotted. Although the uncertainty is sometimes large, the different series are quite distinct in these key points. High $R^{2}$ at the periods mentioned are expected from how they are calculated, but the fact that the $R^{2}$ never reaches unity is notable and is likely due to rounding of index estimates and slight differences in calculation methods from the original TCR assessment (e.g., use of 20 year trend for starting year). A high $R^{2}$ throughout for T140 after the abrupt and strong forcing of $4 \times \mathrm{CO}_{2}$ are consistent with $\mathrm{T} 140$ correlating highly with any of the "strong, advanced warming" scenarios and perhaps related to the fact they both represent quadrupling of $\mathrm{CO}_{2}$.

Under the RCPs, GMSAT rises over the 21st century with a magnitude and rate that depends on the forcing (Figures $2 \mathrm{a}$ and $2 \mathrm{~b}$ ). For GMSAT relative to $\mathrm{PI}$ in the higher two RCPs, $R^{2}$ with ECS rises later than for TCR and T140 and is higher than TCR and comparable to T140 by 2100 (Figures 2c and 2d). For RCP2.6, the $R^{2}$ with each of the transient measures of sensitivity remains higher than ECS but starts to fall by 2100 as the 

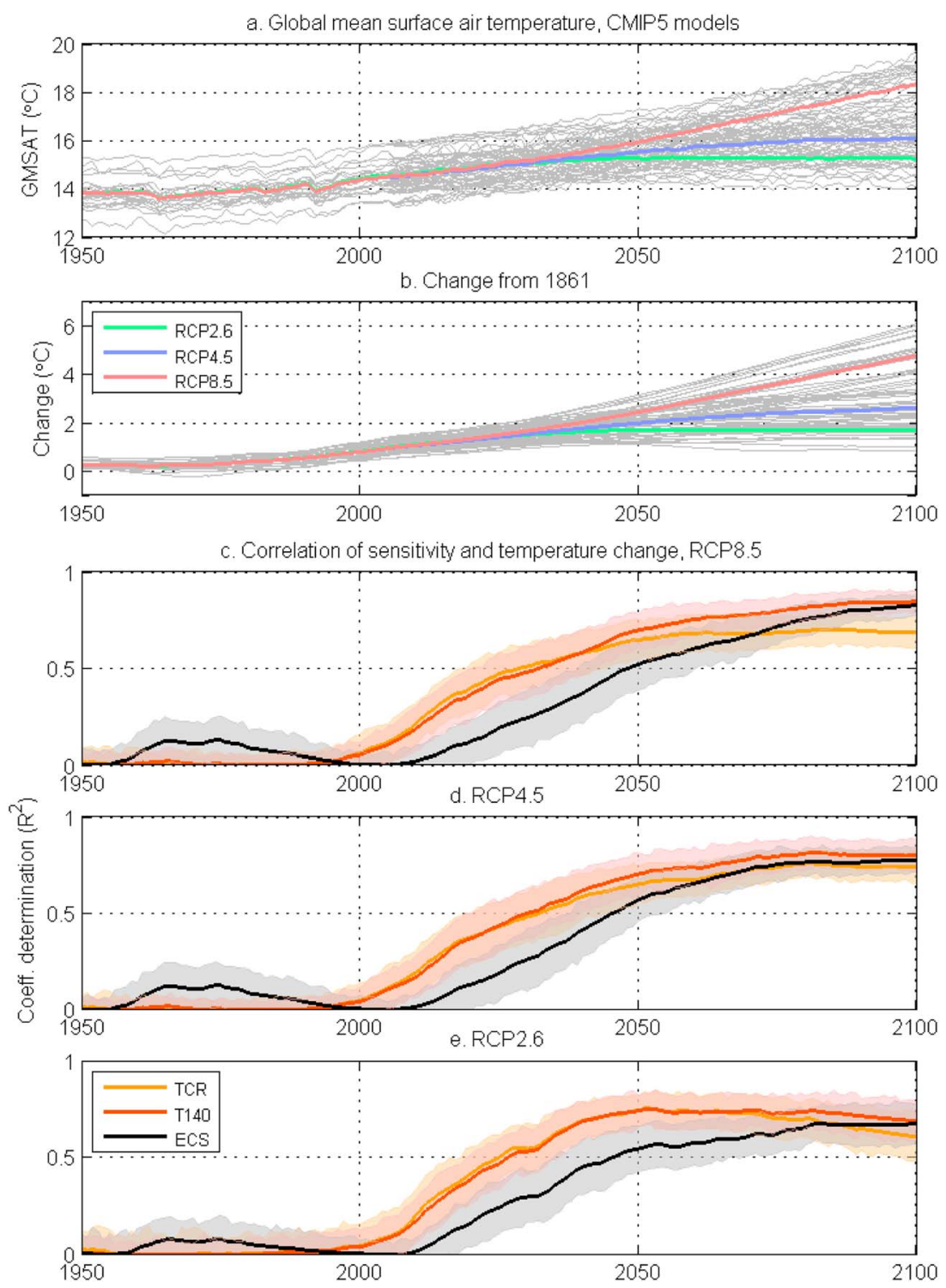

Figure 2. Global mean surface air temperature (GMSAT) and climate sensitivity; (a) time series of GMSAT 1950 to 2100 from up to 24 Coupled Model Intercomparison Project phase 5 (CMIP5) models for simulations from historical and three RCPs; (b) 20 year moving mean GMSAT anomaly from 1950-1880 for historical and RCPs; (c) $R^{2}$ between change in GMSAT and sensitivity estimates for RCP8.5, shading shows \pm 1 standard deviation using a 1,000-member bootstrap; $(\mathrm{d}$ and $\mathrm{e}$ ) as in (c) but for RCP4.5 and RCP2.6, respectively. Individual models in (a) and (b) are shown in gray, the multimodel mean in color.

warming stabilizes (Figure 2e). This relationship between sensitivity and change in GMSAT relative to PI is consistent with the notion that measures of the transient response are more relevant for time-dependent climate change where model-dependent ocean heat uptake is influencing the warming. The results are also consistent with the equilibrium sensitivity index becoming increasingly relevant through time since $\mathrm{PI}$, with a stronger relationship when forcing is sustained (RCP8.5 or RCP4.5) than if it peaks and then falls (RCP2.6).

The lower $R^{2}$ for temperature change and ECS for RCP2.6 is perhaps puzzling, as the climate appears closest to "equilibrated" of the three RCPs. Under RCP2.6, rates of warming become very low and anthropogenic greenhouse forcing decreases after midcentury, so the ratio of the forced signal to the climate variability "noise" becomes low, perhaps explaining the low $R^{2}$. Also, it is likely that large-scale adjustments (e.g., SST patterns) are continuing to occur, and "hysteresis effects" occur which are sensitive to the rapid "ramp upramp down" nature of the forcing (Boucher et al., 2012; Chadwick et al., 2013). These may result in global temperatures less correlated with both ECS and TCR over the period of adjustment. 

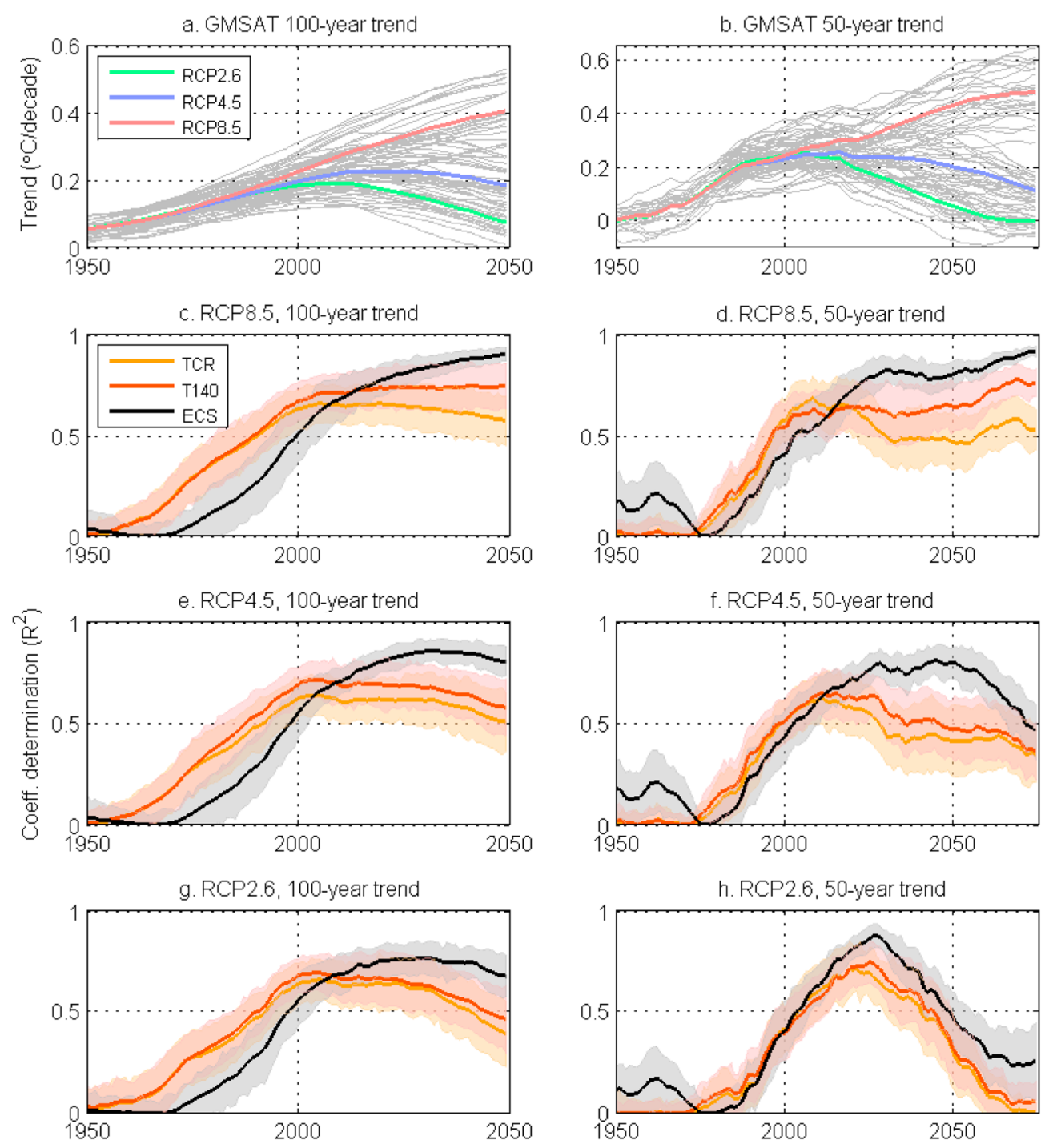

Figure 3. As for Figure 2 but for trends within (left column) 100 year moving window and (right column) 50 year moving window. GMSAT = Global mean surface air temperature.

The $R^{2}$ values over the 20th century are consistently lower than that of the $21 \mathrm{st}$ century, and the plots begin at 1950 because all values prior to 1950 are below 0.2. This is consistent with findings elsewhere that historical changes are more strongly correlated with model forcing while projected changes are more related to model feedback strength (Crook \& Forster, 2011; Forster et al., 2013).

When we examine linear trends in a moving window of 100 years and 50 years (Figure 3 ), the relative strengths of the $R^{2}$ between warming and equilibrium and transient sensitivity measures show some notable features counter to the response since preindustrial times (Figure 2). Here the temperature trend has a higher $R^{2}$ with ECS than transient indices for most windows within the 21 st century (results are very similar when using a moving window of differences between 20 year periods that are 100 years apart such as 1961-1980 minus 1861-1880 through to 2081-2100 minus 1981-2000, not shown.) Similar to Figure 2, the standard deviation of the bootstrapped samples is broad at times, but the different indices are distinct at key points.

The different relationships between sensitivity indices with the two measures of temperature change (Figures 2 and 3) are reflected in the scatterplot, for example, periods under RCP8.5 (Figure 1). For change since PI to 2050, the $R^{2}$ with ECS are lower than for TCR, whereas for the 100 year trend over the 21 st century, the $R^{2}$ is higher for ECS. Notably, for temperature change from PI to 2050 and ECS the intercept is higher and the slope is lower than for transient measures. If we assume that warming should be proportional to the index and the 

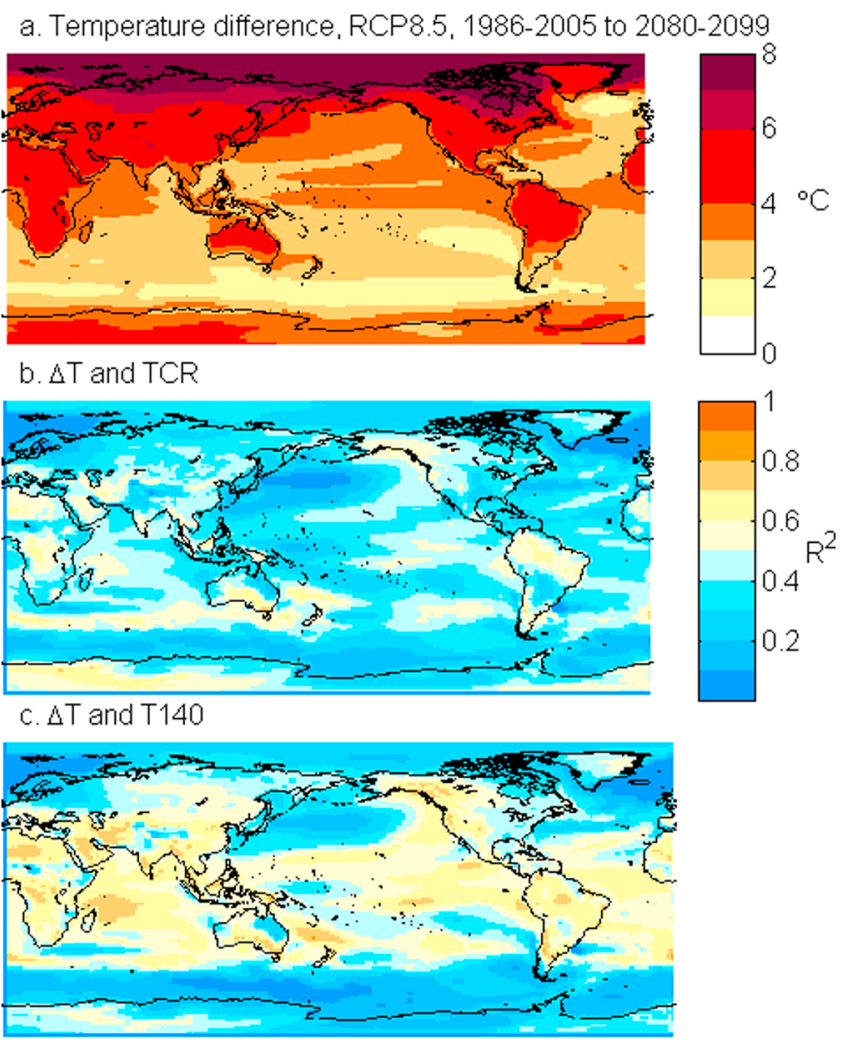

d. $\triangle T$ and ECS
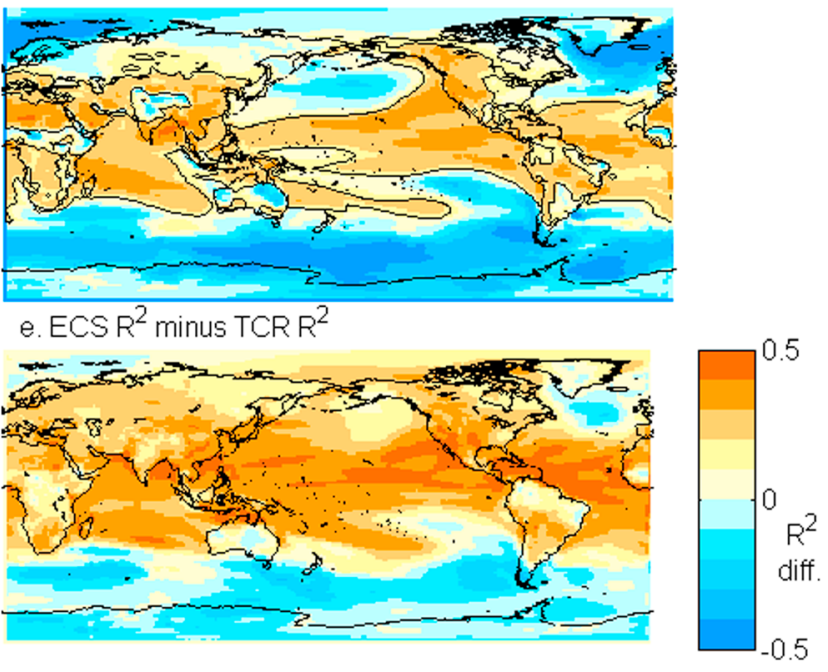

Figure 4. Coefficient of determination $\left(R^{2}\right)$ of the intermodel spread in mean annual temperature difference between 1986-2005 and 2080-2099 under RCP8.5 with climate sensitivity indices; (a) model mean temperature projection; (b) transient climate response (TCR) in 24 Coupled Model Intercomparison Project phase 5 (CMIP5) models; (c) T140 in 24 CMIP5 models; (d) ECS in 20 CMIP5 models (the 0.66 contour is marked); and (e) the difference between panels (b) and (d). ECS = equilibrium climate sensitivity. intercept should be zero, we see the same relative patterns of $R^{2}$ in the different simulations, showing that the result is consistent whether we consider the sensitivity estimates to be idealized indices of nonlinear warming or if we do assume they should be proportional. The $R_{0}{ }^{2}$ using a simpler model and an intercept set to zero shows a similar relative magnitude of temperature change with ECS, T140, and TCR through time (Figures S1C and S1d) as the $R^{2}$ with the modeled intercept (Figures 2c and 3c).

The foregoing analysis considers only the global values of temperature changes, but we might expect regional differences to be important too. Patterns of warming change with time, with Southern Hemisphere highlatitude warming lagging over equatorial or Northern Hemisphere warming (e.g., Armour et al., 2013). Furthermore, correlations of regional temperature change with sensitivity are of great interest, both to explore processes involved in determining sensitivity and also for use in describing uncertainties in regional climate projections. Here we look at change over the 21st century as a time frame relevant to climate projections, which shows some notable spatial features across the globe (Figure 4). There is a similar spatial structure for the $R^{2}$ with each index (pattern correlations of $>0.9$ ), with minima in regions of the least warming, such as the Southern Ocean and North Atlantic, and also minima in the Arctic sea ice zone (Figure 4). There are successively greater global mean values of $R^{2}$ for each index (TCR 0.37, T140 0.48, and ECS 0.56), but the difference is not uniform in space (Figure 4d). ECS shows a higher $R^{2}$ in all regions where values are high, but less where values are low in the Southern Ocean and northern Atlantic Ocean. This appears to reflect that ocean warming in these areas is delayed and not in equilibrium, so TCR explains more variability between models in these areas.

The results suggest that for temperature projections of the 21st century, ECS has a higher $R^{2}$ than T140 or TCR in most inhabited regions, but the $R^{2}$ is only above 0.66 in regions such as western North America, subregions of South America, the western Indian Ocean, North Africa, the Middle East, and East Asia. The highest $R^{2}$ is found broadly across the tropics and subtropics, with maxima in the central and eastern Pacific, possibly as these are areas of low unforced variability (Hawkins \& Sutton, 2012). The spatial patterns are similar for total change in GMSAT from 1861 to 2100 (Figure S3).

\section{Discussion and Conclusions}

TCR is considered more useful than ECS for climate projections of the next few decades (e.g., Knutti et al., 2017). Similarly, it may be expected that TCR or T140 would have a better fit to the model spread in temperature change over the 21 st century for several reasons. Namely, the oceans will not be in equilibrium with the forcing applied, the projected $\mathrm{CO}_{2}$ increase for the remainder of the 21st century is more similar to the method of calculating TCR ( $1 \% \mathrm{CO}_{2}$ simulations), than that of ECS (abrupt $4 \mathrm{xCO}_{2}$ simulations), and the typical time frame of projections of 50-100 years is also more similar to the method of calculating TCR (70 years) than ECS (140 years). However, here we show that ECS explains more variability in the model spread in temperature change over the 21 st century. This result was also found in Grose et al. (2016) and Gregory et al. (2015), but this analysis shows that the $R^{2}$ is greater for ECS than TCR consistently for moving windows after around 2015 (100 year trends for 1966-2065 through to the 100 year trend for 2001-2100; Figure 2c) and 50 year windows for a similar time frame (Figure $2 \mathrm{~d}$ ). This suggests that ECS is in fact the most useful index for describing the model spread in temperature change over the 21 st century for the globe and most regions. 
What causes the higher $R^{2}$ with ECS than with TCR or T140 for projections of the 21 st century? The results do not provide a single clear answer, but some aspects are worth discussion. The effect of a projected reduction in aerosol forcing is expected to introduce some additional noise and reduce the global correlations with sensitivity measures based purely on greenhouse forcing, but this would affect the correlation to both TCR and ECS equally. A substantial fraction of the positive radiative forcing (and subsequent warming) under RCP4.5 comes from removal of the aerosol burden, rather than increases in $\mathrm{CO}_{2}$ (Rotstayn et al., 2013), but in RCP8.5 the warming is dominated by $\mathrm{CO}_{2}$ increases (van Vuuren et al., 2011). However, the dominance of ECS in RCP4.5 is greater than for RCP8.5 in the mid-21st century (Figures $2 \mathrm{c}$ and $2 \mathrm{f}$ ). So the noise introduced by aerosol forcing changes does not explain the results.

Instead, part of the explanation may be that the pattern and rate of oceanic heat uptake is critical to setting the timescale of 21st century warming in individual models (Geoffroy et al., 2013; Gregory et al., 2015; Held et al., 2010). Under the relatively slow rate of warming in the first 70 years of $1 \%$ compounded warming, uptake rates may be expected to differ markedly from that of more advanced warming, such as the accelerated warming found in the following 70 years (Gregory et al., 2015) as the distribution of surface warming evolves closer to the pattern of equilibrated warming (Armour et al., 2013). The uptake rates under TCR, then, are inappropriate for the period of rapid warming in the 21 st century, reducing correlation.

Climate feedbacks, too, are sensitive to the patterns of warming (Armour et al., 2013; Gregory \& Andrews, 2016; Zhou et al., 2016) and become relatively more important than the ocean heat uptake efficiency in determining the model spread as time passes (Forster et al., 2013). The pattern, then, of feedbacks may be critical to the closer agreement of ECS to the response under strong warming. Feedbacks also behave in a nonlinear way as warming continues. The increase in $R^{2}$ between ECS and GMSAT out to 2100 (and potentially beyond) under sustained forcing of RCP8.5 in Figure 1c is presumably a factor of this increased dominance of feedbacks over both ocean heat content and forcing spread in determining the overall response. Further work would be needed to clarify these processes, including a study of the relative rates of ocean heat uptake, linked with the evolution of feedbacks under differing experiments in models.

The results presented here are specific to CMIP5 climate models, and also to the RCPs, and are not evaluated against other lines of evidence. The prescribed greenhouse and aerosol forcings in the RCPs may not be accurate in the past or future. Also, model errors may play a role in these $R^{2}$ values, including in the response to aerosol and greenhouse forcings, ocean heat uptake efficiency, and climate feedbacks. So the results may not give us insights into the broader concepts of sensitivity outside models. At the least, the results are useful for interpreting sensitivity measures in terms of temperature projections within climate models, and in fact that is the reason for their being defined originally, as benchmarks for comparison of models. The results suggest which index can be the most useful in explaining the model spread for both change since PI (T140), and change over the 21 st century (ECS).

The results show that the relationship between the model spread in projected temperature and sensitivity indices varies markedly in space. The coefficient of determination is higher broadly in areas of the tropics and the midlatitudes, so sensitivity indices will be more useful to describe projections in these areas. Regions where sensitivity has a low $R^{2}$ with temperature change include areas of delayed warming (such as the Southern Ocean) and areas of sea ice cover, where regional albedo and cloud feedback processes are known to cause a large fraction of the spread (Crook et al., 2011; Winton, 2006). Global-scale sensitivity indices will not be as useful to regional projections here.

It appears that ECS is in fact more useful than TCR for climate model projections of the 21st century in terms of indicating the magnitude of change for a prescribed RCP scenario. This is counter to the expectations since the time frame is generally considered to be in the realm of transient climate change, and added noise from aerosol forcing does not explain the results. More work and possibly the analysis of different model simulations are needed to understand and quantify the specific reasons for these relationships.

\section{References}

Andrews, T., Gregory, J. M., Webb, M. J., \& Taylor, K. E. (2012). Forcing, feedbacks and climate sensitivity in CMIP5 coupled atmosphere-ocean climate models. Geophysical Research Letters, 39, L09712. https://doi.org/10.01029/02012GL051607

Armour, K. C., Bitz, C. M., \& Roe, G. H. (2013). Time-varying climate sensitivity from regional feedbacks. Journal of Climate, 26(13), 4518-4534. https://doi.org/10.1175/JCLI-D-12-00544.1 
Boucher, O., Halloran, P. R., Burke, E. J., Doutriaux-Boucher, M., Jones, C. D., Lowe, J., et al. (2012). Reversibility in an Earth System model in response to $\mathrm{CO}_{2}$ concentration changes. Environmental Research Letters, 7(2), 024013. https://doi.org/10.1088/1748-9326/7/2/024013

Chadwick, R., Wu, P., Good, P., \& Andrews, T. (2013). Asymmetries in tropical rainfall and circulation patterns in idealised $\mathrm{CO}_{2}$ removal experiments. Climate Dynamics, 40(1-2), 295-316. https://doi.org/10.1007/s00382-012-1287-2

Collins, M., Knutti, R., Arblaster, J., Dufresne, J.-L., Fichefet, T., Friedlingstein, P., et al. (2013). Long-term climate change: Projections, commitments and irreversibility. In T. F. Stocker, et al. (Eds.), Climate change 2013: The physical science basis. Contribution of working group I to the Fifth Assessment Report of the Intergovernmental Panel on Climate Change (pp. 1029-1136). Cambridge, United Kingdom and New York: Cambridge University Press. https://doi.org/10.1017/CBO9781107415324.024

Cowtan, K., \& Way, R. G. (2014). Coverage bias in the HadCRUT4 temperature series and its impact on recent temperature trends. Quarterly Journal of the Royal Meteorological Society, 140(683), 1935-1944. https://doi.org/10.1002/qj.2297

Crook, J. A., \& Forster, P. M. (2011). A balance between radiative forcing and climate feedback in the modeled 20th century temperature response. Journal of Geophysical Research, 116, D17108. https://doi.org/10.1029/2011JD015924

Crook, J. A., Forster, P. M., \& Stuber, N. (2011). Spatial patterns of modeled climate feedback and contributions to temperature response and polar amplification. Journal of Climate, 24(14), 3575-3592. https://doi.org/10.1175/2011JCLI3863.1

Flato, G. M., Marozke, J., Abiodun, B., Braconnot, P., Chou, S. C., Collins, W., et al. (2013). Chapter 9: Evaluation of climate models. In T. F. Stocker, et al. (Eds.), Climate change 2013: The physical science basis. Contribution of working group I to the Fifth Assessment Report of the Intergovernmental Panel on Climate Change (pp. 741-866). Cambridge, United Kingdom and New York: Cambridge University Press.

Forster, P. M., Andrews, T., Good, P., Gregory, J. M., Jackson, L. S., \& Zelinka, M. (2013). Evaluating adjusted forcing and model spread for historical and future scenarios in the CMIP5 generation of climate models. Journal of Geophysical Research: Atmospheres, 118, 1139-1150. https://doi.org/10.1002/jgrd.50174

Geoffroy, O., Saint-Martin, D., Bellon, G., Voldoire, A., Olivié, D. J. L., \& Tytéca, S. (2013). Transient climate response in a two-layer energybalance model. Part II: Representation of the efficacy of deep-ocean heat uptake and validation for CMIP5 AOGCMs. Journal of Climate, 26(6), 1859-1876. https://doi.org/10.1175/JCLI-D-12-00196.1

Gregory, J. M., \& Andrews, T. (2016). Variation in climate sensitivity and feedback parameters during the historical period. Geophysical Research Letters, 43, 3911-3920. https://doi.org/10.1002/2016GL068406

Gregory, J. M., Andrews, T., \& Good, P. (2015). The inconstancy of the transient climate response parameter under increasing $\mathrm{CO}_{2}$. Philosophical Transactions of the Royal Society A: Mathematical, Physical and Engineering Sciences, 373(2054), 20140417. https://doi.org/ 10.1098/rsta.2014.0417

Gregory, J. M., \& Forster, P. M. (2008). Transient climate response estimated from radiative forcing and observed temperature change. Journal of Geophysical Research, 113, D23105. https://doi.org/10.1029/2008JD010405

Gregory, J. M., Ingram, W. J., Palmer, M. A., Jones, G. S., Stott, P. A., Thorpe, R. B., et al. (2004). A new method for diagnosing radiative forcing and climate sensitivity. Geophysical Research Letters, 31, L03205. https://doi.org/10.1029/2003GL018747

Grose, M. R., Colman, R., Bhend, J., \& Moise, A. F. (2016). Limits to global and Australian temperature change this century based on expert judgment of climate sensitivity. Climate Dynamics, 48(9-10), 3325-3339. https://doi.org/10.1007/s00382-016-3269-2

Hawkins, E., \& Sutton, R. (2012). Time of emergence of climate signals. Geophysical Research Letters, 39, L01702. https://doi.org/10.1029/ 2011 GL050087

Held, I. M., Winton, M., Takahashi, K., Delworth, T., Zeng, F., \& Vallis, G. K. (2010). Probing the fast and slow components of global warming by returning abruptly to preindustrial forcing. Journal of Climate, 23(9), 2418-2427. https://doi.org/10.1175/2009JCLI3466.1

IPCC (2013). In T. F. Stocker, et al. (Eds.), Climate change 2013: The physical science basis. Contribution of working group I to the Fifth Assessment Report of the Intergovernmental Panel on Climate Change. Cambridge, United Kingdom and New York: Cambridge University Press.

Knutti, R., Masson, D., \& Gettelman, A. (2013). Climate model genealogy: Generation CMIP5 and how we got there. Geophysical Research Letters, 40, 1194-1199. https://doi.org/10.1002/grl.50256

Knutti, R., Rugenstein, M. A. A., \& Hegerl, G. C. (2017). Beyond equilibrium sensitivity. Nature Geoscience, 10(10), 727-736. https://doi.org/ 10.1038/ngeo3017

Kuhlbrodt, T., \& Gregory, J. M. (2012). Ocean heat uptake and its consequences for the magnitude of sea level rise and climate change. Geophysical Research Letters, 39, L18608. https://doi.org/10.1029/2012GL052952

Masson-Delmotte, V., Schulz, M., Abe-Ouchi, A., Beer, J., Ganopolski, J., González Rouco, J. F., et al. (2013). In T. F. Stocker, et al. (Eds.), Information from paleoclimate archives. Climate change 2013: The physical science basis. Contribution of working group I to the Fifth Assessment Report of the Intergovernmental Panel on Climate Change (pp. 383-464). Cambridge, United Kingdom and New York: Cambridge University Press. https://doi.org/10.1017/CBO9781107415324.013

Mitchell, T. D. (2003). Pattern scaling: An examination of the accuracy of the technique for describing future climates. Climatic Change, 60(3), 217-242. https://doi.org/10.1023/A:1026035305597

Murphy, J. M. (1995). Transient response of the Hadley Centre coupled ocean-atmosphere model to increasing carbon dioxide. Part 1: Contro climate and flux adjustment. Journal of Climate, 8(1), 36-56. https://doi.org/10.1175/1520-0442(1995)008\%3C0036:TROTHC\%3E2.0.CO;2

Richardson, M., Cowtan, K., Hawkins, E., \& Stolpe, M. B. (2016). Reconciled climate response estimates from climate models and the energy budget of Earth. Nature Climate Change, 6(10), 931-935. https://doi.org/10.1038/nclimate3066

Rotstayn, L. D., Collier, M. A., Chrastansky, A., Jeffrey, S. J., \& Luo, J.-J. (2013). Projected effects of declining aerosols in RCP4.5: Unmasking global warming? Atmospheric Chemistry and Physics, 13(21), 10,883-10,905. https://doi.org/10.5194/acp-13-10883-2013

Seneviratne, S. I., Donat, M. G., Pitman, A. J., Knutti, R., \& Wilby, R. L. (2016). Allowable $\mathrm{CO}_{2}$ emissions based on regional and impact-related climate targets. Nature, 529(7587), 477-483. https://doi.org/10.1038/nature16542

Taylor, K. E., Stouffer, R. J., \& Meehl, G. A. (2012). An overview of CMIP5 and the experiment design. Bulletin of the American Meteorological Society, 93(4), 485-498. https://doi.org/10.1175/BAMS-D-11-00094.1

Tebaldi, C., \& Arblaster, J. (2014). Pattern scaling: Its strengths and limitations, and an update on the latest model simulations. Climatic Change, 122(3), 459-471. https://doi.org/10.1007/s10584-013-1032-9

van Vuuren, D., Edmonds, J., Kainuma, M., Riahi, K., Thomson, A., Hibbard, K., et al. (2011). The representative concentration pathways: An overview. Climatic Change, 109(1-2), 5-31. https://doi.org/10.1007/s10584-011-0148-z

Whetton, P., Macadam, I., Bathols, J., \& O'Grady, J. (2007). Assessment of the use of current climate patterns to evaluate regional enhanced greenhouse response patterns of climate models. Geophysical Research Letters, 34, L14701. https://doi.org/10.1029/2007GL030025

Winton, M. (2006). Amplified Arctic climate change: What does surface albedo feedback have to do ith it? Geophysical Research Letters, 33, L03701. https://doi.org/10.1029/2005GL025244

Zhou, C., Zelinka, M. D., \& Klein, S. A. (2016). Impact of decadal cloud variations on the Earth's energy budget. Nature Geoscience, 9(12), 871-874. https://doi.org/10.1038/ngeo2828 